\title{
Composição mineral e sintomas visuais de deficiências de nutrientes em plantas de pimenta-longa (Piper hispidinervum C. DC.)
}

Ismael de Jesus Matos VIÉGAS ${ }^{1}$, Gizele Odete de SOUSA ${ }^{1}$, Adelícia Fernandes da SILVA ${ }^{1}$, Janice Guedes de CARVALHO $^{2}$, Martinha Moura LIMA ${ }^{1}$

\section{RESUMO}

A pimenta-longa (Piper hispidinervum C. DC.) é uma das principais fontes alternativas para a produçáo de safrol empregado como matéria prima na fabricação de inseticidas naturais e aromatizantes. O objetivo da pesquisa foi avaliar o efeito da omissão dos macronutrientes e micronutrientes, sobre a composição mineral de plantas de pimenta-longa, e caracterizar os sintomas de deficiências decorrentes dessa limitação, utilizando-se da técnica do elemento faltante. O experimento foi conduzido em casa de vegetação, com quatro repetiçóes e doze tratamentos, completo e omissão individual de $\mathrm{N}, \mathrm{P}, \mathrm{K}, \mathrm{Ca}, \mathrm{Mg}, \mathrm{S}, \mathrm{B}, \mathrm{Cu}, \mathrm{Fe}$, $\mathrm{Mn}$ e $\mathrm{Zn}$ em delineamento inteiramente ao acaso. Os valores dos teores foliares nos tratamentos com omissáo dos nutrientes foram inferiores àqueles obtidos no tratamento completo. As omissóes individuais dos nutrientes promoveram alteraçóes na composição mineral de macro e micronutrientes. Os teores de macronutrientes $\left(\mathrm{g} \mathrm{kg}^{-1}\right)$ e micronutrientes $\left(\mathrm{mg} \mathrm{kg}^{-1}\right) \mathrm{obtidos}$ nas folhas sem (completo) e com sintomas de deficiências (omissóes) foram, respectivamente: $\mathrm{N}=18,32 ; \mathrm{P}=7,02 ; \mathrm{K}=22,17$; $\mathrm{Ca}=15,75 ; \mathrm{Mg}=8,25 ; \mathrm{S}=5,12 ; \mathrm{B}=42,25 ; \mathrm{Fe}=325,00 ; \mathrm{Mn}=100 ; \mathrm{Zn}=61,50$, com deficiência: $\mathrm{N}=8,98 ; \mathrm{P}=2,52 ; \mathrm{K}=$ 8,$57 ; \mathrm{Ca}=10,20 ; \mathrm{Mg}=1,85 ; \mathrm{S}=0,90 ; \mathrm{B}=15,50 ; \mathrm{Fe}=234,00 ; \mathrm{Mn}=55 ; \mathrm{Zn}=53$.

PALAVRAS CHAVE: nutrição de plantas, sintomas de deficiência, piperácea.

\section{Mineral composition and visual symptoms of nutrients deficiencies in long pepper plants (Piper hispidinervum C. DC.)}

\begin{abstract}
The long pepper (Piper hispidinervum C. DC.) is one of the main alternative sources for the production of safrol used as raw material in the manufacture of insecticides and natural flavoring. The objective of this research was to evaluate the effect of omission macronutrients and micronutrients, on the mineral composition of long pepper plants, and featuring the symptoms of deficiencies resulting from this limitation, using the missing element technique. The experiment was conducted in a greenhouse, with four replicates and twelve treatments, complete and individual omission of $\mathrm{N}, \mathrm{P}, \mathrm{K}, \mathrm{Ca}, \mathrm{Mg}, \mathrm{S}, \mathrm{B}, \mathrm{Cu}, \mathrm{Fe}, \mathrm{Mn}$ and $\mathrm{Zn}$ in a completely randomized design. Foliar levels in treatments with the omission of nutrients were lower than those obtained in the complete treatment. The omission of individual nutrients promotes changes in the mineral composition of macro and micronutrients. The levels of macronutrients $\left(\mathrm{g} \mathrm{kg}^{-1}\right)$ and micronutrients $\left(\mathrm{mg} \mathrm{kg}^{-1}\right)$ achieved in the leaves without (complete) and with symptoms of deficiencies (omissions) were, respectively: $\mathrm{N}=18,32 ; \mathrm{P}=7,02 ; \mathrm{K}=22,17 ; \mathrm{Ca}=15,75 ; \mathrm{Mg}=8,25$; $\mathrm{S}=5,12 ; \mathrm{B}=42,25 ; \mathrm{Fe}=325,00 ; \mathrm{Mn}=100 ; \mathrm{Zn}=61,50$, with deficiencies: $\mathrm{N}=8,98 ; \mathrm{P}=2,52 ; \mathrm{K}=8,57 ; \mathrm{Ca}=10,20 ; \mathrm{Mg}$ $=1,85 ; \mathrm{S}=0,90 ; \mathrm{B}=15,50 ; \mathrm{Fe}=234,00 ; \mathrm{Mn}=55 ; \mathrm{Zn}=53$.
\end{abstract}

KEYWORDS: mineral nutrition, deficiency symptoms, piperaceae. 


\section{INTRODUÇÃO}

A Amazônia Brasileira é um reservatório rico em espécies vegetais, pouco pesquisada e explorada economicamente. Dentre estas, destaca-se a pimenta-longa (Piper hispidinervum C. DC.), que ocorre no Estado do Acre e se desenvolve normalmente em áreas de pousio, que por conter óleos essenciais para a produção de safrol, não possui processo de exploração destrutiva, como acontece com outras espécies produtoras desse óleo essencial, onde o estabelecimento de um sistema de produção é de fundamental importância. A pimenta-longa possui em suas folhas teores que variam de 90 a $94 \%$ do óleo essencial safrol (Santiago et al. 2001).

De modo geral, estudos sobre nutrição e adubação de plantas produtoras de óleo de origem amazônica e de interesse econômico, ainda são bastante incipientes, sendo poucas as informaçôes sobre exigências nutricionais das espécies da região, como é o caso da pimenta-longa. Na literatura são encontrados trabalhos desenvolvidos por Brasil e Viégas (1998), que avaliaram o efeito da adubação mineral na produção de matéria seca de pimenta-longa, e Sousa et al. (2001), que estudaram o efeito da adubação e do calcário na produção de matéria seca e de óleo essencial de pimenta-longa. Nesse contexto, há necessidade de pesquisas, em várias áreas, visando compor um sistema de produção sustentável para o cultivo de pimenta-longa, dentre as quais as de fertilidade e nutrição de plantas.

O objetivo deste trabalho foi avaliar o efeito da limitação dos macro e micronutrientes, sobre a composição mineral de plantas de pimenta-longa e caracterizar os sintomas de deficiências decorrentes dessa limitação, baseando-se na técnica do elemento faltante, sob condiçôes de casa de vegetação.

\section{MATERIAL E MÉTODOS}

$\mathrm{O}$ experimento foi conduzido em casa de vegetação da Embrapa Amazônia Oriental, em Belém-PA, com sementes de pimenta-longa (Piper hispidinervum C. DC.), provenientes do Centro de Pesquisa Agroflorestal do Acre.

A semeadura ocorreu em bandejas, contendo mistura de terra preta e serragem na proporção de 1:1, com germinaçáo 10 dias após a semeadura.

Quando as plantas estavam com quatro folhas maduras expandidas (aproximadamente $10 \mathrm{~cm}$ de comprimento) ou 60 dias de idade, foram selecionadas e transplantadas, colocandose uma muda por vaso, com capacidade para 3 litros. Foi utilizado como substrato o quartzo moído, e as plantas foram irrigadas diariamente com solução nutritiva de Bolle-Jones (1954), Tabela 1, utilizando sais PA (para análise), modificada para a concentraçáo de $0,5 \mathrm{M}$ para $1 \mathrm{M}$ para o $\mathrm{K}_{2} \mathrm{SO}_{4}$ e de 1 $\mathrm{M}$ para $0,5 \mathrm{M}$ para o $\mathrm{Mg}\left(\mathrm{NO}_{3}\right)_{2}$, na proporção de $1: 10$, com água destilada, durante 30 dias, transcorridos mais 25 dias, a solução nutritiva foi substituída para a proporção de 1:5. Aos 60 dias após o plantio, iniciaram-se os tratamentos com soluçáo nutritiva na proporção de 1:1 (carga total), a qual era drenada no fim da tarde, sendo renovada quinzenalmente, tendo-se o cuidado de verificar diariamente o nível da solução nos frascos coletores, completando-se o volume para um litro, pela adição de água destilada, ocasiáo em que era procedida a determinaçáo do $\mathrm{pH}$, onde o mesmo era mantido em torno de 5,5 .

Os tratamentos utilizados no experimento foram os seguintes: Completo, $-\mathrm{N},-\mathrm{P},-\mathrm{K},-\mathrm{Ca},-\mathrm{Mg},-\mathrm{S},-\mathrm{B},-\mathrm{Cu}$, $-\mathrm{Fe},-\mathrm{Mn}$ e $-\mathrm{Zn}$.

O delineamento experimental utilizado foi o inteiramente ao acaso, com 12 tratamentos e quatro repetiçóes.

A evoluçáo dos sintomas de deficiências dos nutrientes foi acompanhada e descrita desde seu início até sua definição, sendo fotografadas. As plantas de cada tratamento foram coletadas à medida que os sintomas visuais se definiram. Estas foram divididas em folhas, caules e raízes, lavadas em água destilada e colocadas em estufa com circulação forçada de ar a $70^{\circ} \mathrm{C}$, até obtenção de peso constante. Posteriormente, foi procedida a moagem do material em moinho Willey de peneira de 20 mesh, para posterior análise química das amostras.

Foram realizadas as determinaçôes analíticas dos teores de nitrogênio, fósforo, potássio, cálcio, magnésio, enxofre, boro, cobre, ferro, manganês e zinco nas folhas. $\mathrm{O} N$ foi determinado após digestão sulfúrica, pelo método de Kjeldahl. O P, K, Ca, $\mathrm{Mg}, \mathrm{S}, \mathrm{Cu}, \mathrm{Fe}, \mathrm{Mn}$ e $\mathrm{Zn}$ através da digestão nitro-perclórica; sendo $\mathrm{P}$ dosado por colorimetria do molibdato-vanadato; $\mathrm{K}$ por fotometria de chama; $\mathrm{Ca}$ e $\mathrm{Mg}$ por espectofotometria de absorção atômica; $\mathrm{S}$ por turbidimetria; $\mathrm{Cu}, \mathrm{Fe}, \mathrm{Mn}$ e $\mathrm{Zn}$ por espectofotometria de absorçấo atômica; e B por colorimetria (Azometina-H).

Os dados obtidos de teor foliar foram submetidos à análise de variância através do programa Assistat, e as médias dos tratamentos com omissão dos nutrientes foram comparadas com o tratamento completo utilizando-se o teste bilateral de Dunnet, a $5 \%$ de probabilidade.

\section{RESULTADOS E DISCUSSÃO}

\section{Sintomas de deficiências de nutrientes}

\section{Nitrogênio}

Os primeiros sintomas de deficiência a se manifestarem foram os de nitrogênio, 13 dias após o início dos tratamentos, indicando ser esse nutriente, limitante para a pimenta-longa. Os sintomas iniciais surgiram nas folhas mais velhas com coloração verde-amarelada, seguida por clorose generalizada e evoluindo para necrose (Figura 1). Veloso e Muraoka 
ACTA

AMAZONICA
Composição mineral e sintomas visuais de deficiências de nutrientes em

plantas de pimenta-longa (Piper hispidinervum C. DC.)

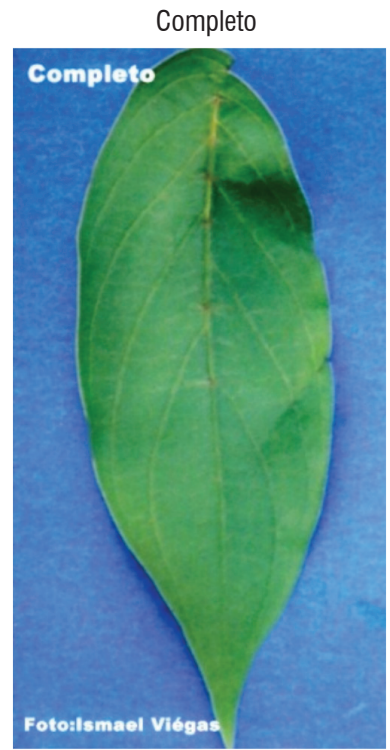

Omissão de K

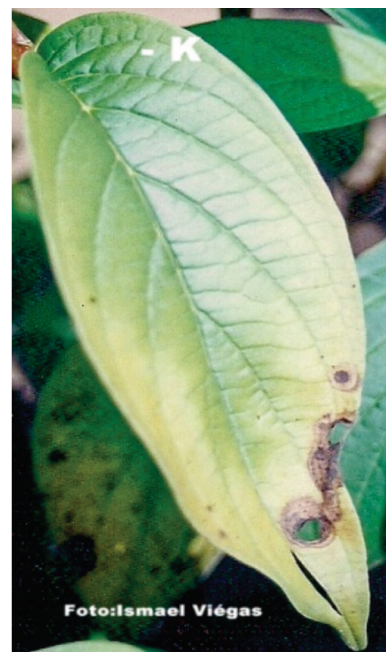

Omissão de B

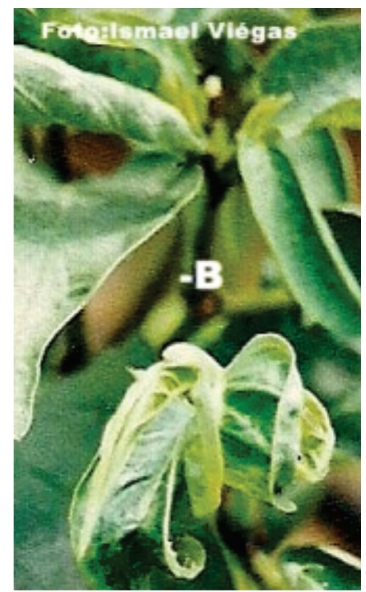

Omissão de N

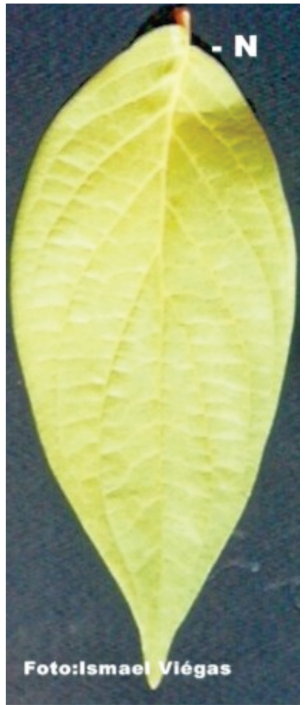

Omissão de Ca

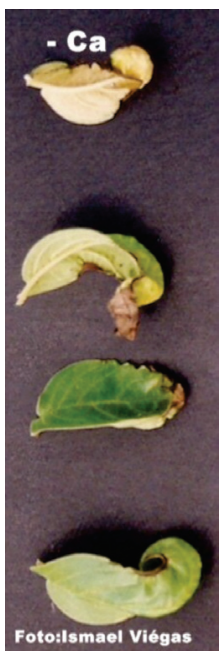

Omissão de Fe

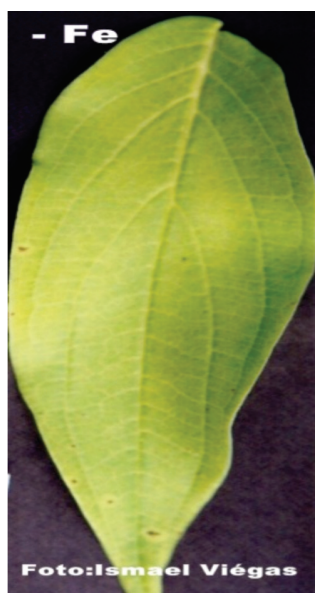

Omissão de P

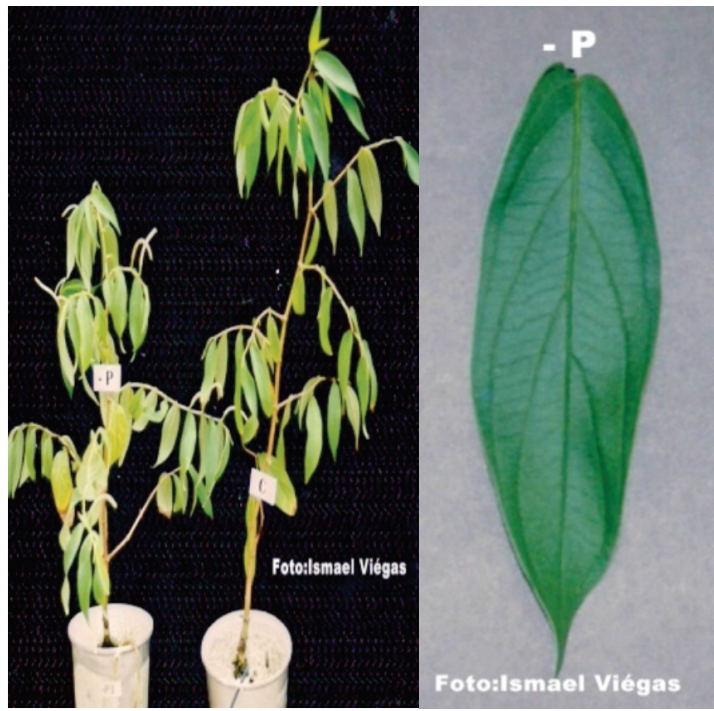

Omissão de Mg

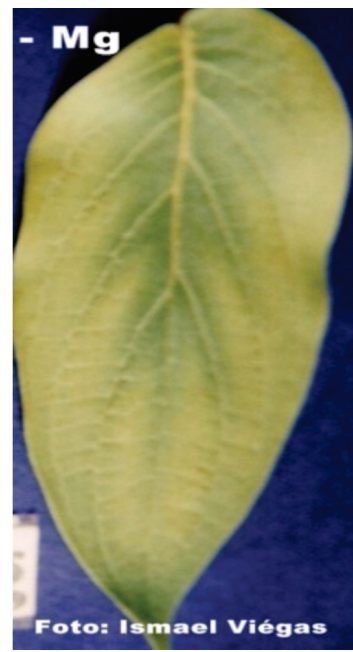

Omissão de Mn

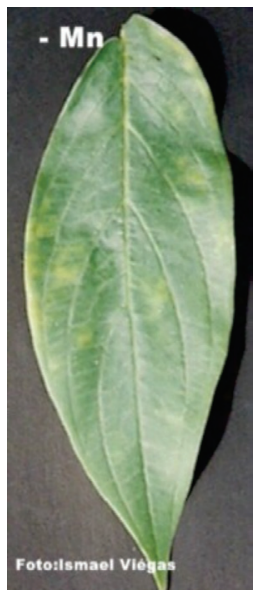

Omissão de S

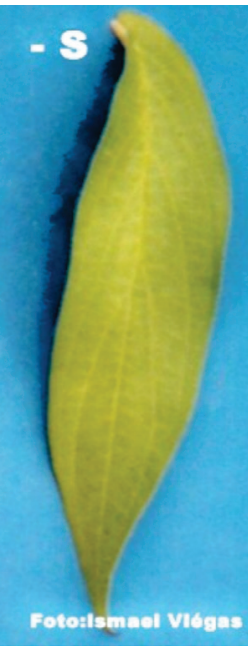

Omissão de Zn

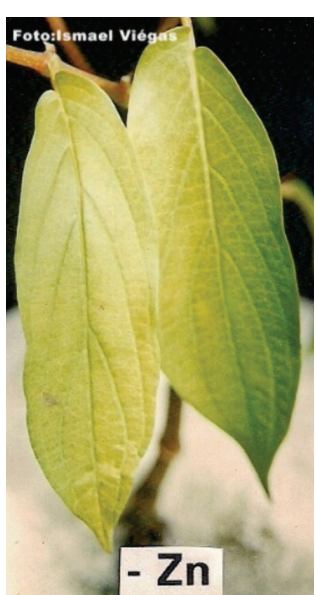

Figura 1- Sintomas de deficiência nutricional em plantas de pimenta-longa (Piper hispidinervum C. DC.) submetidas aos tratamentos em solução nutritiva completa e com omissão de macro e micronutrientes. 
Tabela 1- Composição química das soluções nutritivas estoques, em molar (M), e dos tratamentos, em mL.L-1, utilizadas no experimento (Bolle-Jones, 1954).

\begin{tabular}{|c|c|c|c|c|c|c|c|c|}
\hline \multirow{2}{*}{ Solução Estoque } & \multirow{2}{*}{ Concentração (M) } & \multicolumn{7}{|c|}{ Tratamentos (mL.L-1) } \\
\hline & & Completa & $-\mathrm{N}$ & $-P$ & $-K$ & $-\mathrm{Ca}$ & $-\mathrm{Mg}$ & $-S$ \\
\hline $\mathrm{NaH}_{2} \mathrm{PO}_{4}$ & 1 & 1 & 1 & - & 1 & 1 & 1 & 1 \\
\hline $\mathrm{Ca}\left(\mathrm{NO}_{3}\right)_{2} \cdot 4 \mathrm{H}_{2} \mathrm{O}$ & 1 & 2 & - & 2 & 2 & - & 2 & 2 \\
\hline $\mathrm{KNO}_{3}$ & 1 & 1 & - & 1 & - & 1 & 3 & 1 \\
\hline $\mathrm{K}_{2} \mathrm{SO}_{4}$ & 1 & 2 & 2 & 2 & - & 2 & 3 & 1 \\
\hline $\mathrm{MgSO}_{4}$ & 0,5 & 2,5 & 2,5 & 2,5 & 2,5 & 2,5 & - & - \\
\hline$\left(\mathrm{NH}_{4}\right)_{2} \mathrm{SO}_{4}$ & 1 & 1,5 & - & 1,5 & 2 & 2,5 & 2 & - \\
\hline $\mathrm{CaSO}_{4} \cdot 2 \mathrm{H}_{2} \mathrm{O}$ & 0,01 & - & 200 & - & - & - & - & - \\
\hline $\mathrm{KH}_{2} \mathrm{PO}_{4}$ & 1 & - & 1 & - & - & - & 1 & 1 \\
\hline $\mathrm{Mg}\left(\mathrm{NO}_{3}\right)_{2}$ & 0,5 & - & - & - & - & - & - & 2,5 \\
\hline $\mathrm{NaNO}_{3}$ & 1 & - & - & 1 & - & - & - & - \\
\hline Sol. $A^{\star}$ & - & 1 & 1 & 1 & 1 & 1 & 1 & 1 \\
\hline Sol.Fe-EDTA ** & - & 1 & 1 & 1 & 1 & 1 & 1 & 1 \\
\hline
\end{tabular}

*Composição química da solução A: 412 mg de H3B03; 1750 mg de MnS04; 250 mg de CuS04.5H20; 43,1 mg de Mo03; 287 mg de ZnS04.7H20, por litro de solução. **Composição química da solução de Fe-EDTA: $26,1 \mathrm{~g}$ de Na2-EDTA, 89,2 mL de NaOH N; $24 \mathrm{~g}$ de FeSO4.7H2), por litro de solução.

(1993) descrevem sintomas semelhantes em plantas de pimenta-do-reino, assim como Maffeis et al. (2000) em Eucalyptus citriodora, Gonçalves et al. (2006), em mudas de umbuzeiro, Silva et al. (2009), em plantas de pinhão-manso, e Benedetti et al. (2009), em plantas de espinheira-santa. A coloração amarelada das folhas está associada com a menor produção de clorofila e com modificaçóes na forma e na degradação de cloroplastos (Epstein e Bloom 2006; Malavolta 2006). Importância do nitrogênio para pimenta-longa foi constatada por Brasil e Viégas (1998), ao verificarem aumento na produçáo de matéria seca, com a aplicação deste macronutriente na presença de fósforo e potássio.

\section{Fósforo}

Para o fósforo, os sintomas de deficiências surgiram nas folhas mais velhas, aos 85 dias, com coloração verde-escura e brilhosa, quando comparadas com as do tratamento completo (Figura 1). Esses sintomas de deficiência de fósforo em pimenta-longa são semelhantes aos descritos por Veloso e Muraoka (1993), em plantas de pimenta-do-reino, Lavres Júnior et al. (2005), em mamona cultivar Íris, e por Silva et al. (2011), em plantas de nim.

Plantas com deficiência em fósforo têm o crescimento retardado, por serem afetados por processos como síntese protéica, ácidos nucléicos, atraso no florescimento e crescimento, gemas laterais dormentes, número reduzido de frutos e sementes, ou seja, com a deficiência de fósforo há redução dos compostos armazenadores de alta energia, como o ATP (Trifosfato de Adenosina). É através da utilizaçáo dessa energia, que a semente germina, a planta efetua a fotossíntese, absorve de forma ativa os nutrientes do solo e sintetiza vários compostos orgânicos (Viégas et al. 2011). O elemento está envolvido em funçóes essenciais do metabolismo celular, atuando na síntese de metabólitos e moléculas complexas como o DNA, RNA e fosfolipídeos, na cadeia de transporte de elétrons, reaçóes redoxes promovendo a regulação da taxa de diversas reaçóes enzimáticas e processos metabólicos, como respiração e fotossíntese.

Sousa et al. (2001), estudando a adubação NPK em pimenta-longa concluiu ser fósforo o nutriente de efeito mais pronunciado em aumentar a produção de matéria seca de ramos e folhas, uma evidência de sua importância para essa espécie.

\section{Potássio}

Aos 45 dias de início dos tratamentos, surgiram os primeiros sinais de deficiência de potássio, caracterizando-se, inicialmente, por uma clorose ao longo das bordas das folhas mais velhas, expandindo-se em direção à nervura central; com a intensidade da deficiência, toda a lâmina foliar ficou clorótica, surgindo, posteriormente, necrose em bordas e ápices das folhas (Figura 1). Resultados semelhantes foram obtidos por Maffeis et al. (2000), em plantas de Eucalyptus citriodora, Sarcinelli et al. (2004), em mudas de Acacia holosericea, Wallau et al. (2008a), em mudas de mogno, e Silva et al. (2009), em plantas de pinhão-manso. Segundo Epstein e Bloom (2006), em plantas com deficiência em potássio, os compostos nitrogenados solúveis, inclusive as aminas putrescinas e agmatina, muitas vezes, se acumulam, sendo esta última, provavelmente, responsável pelas manchas necróticas que aparecem nas folhas deficientes nesse nutriente.

\section{Cálcio}

Os sintomas de deficiência de cálcio em pimenta-longa surgiram aos 53 dias, após iniciados os tratamentos, ocorrendo redução drástica em crescimento das plantas e número 
de folhas e queima da gema apical; as folhas mais jovens apresentaram-se deformadas, enroladas para a face inferior, à semelhança de "gancho" e ápices necrosados (Figura 1). Lavres Júnior et al. (2005), trabalhando com mamona, cultivar Î́ris, Camargos et al. (2002), em mudas de castanheira-do-brasil, e Silveira et al. (2002), com clone híbrido de Eucalyptus grandis $\mathrm{x}$ Eucalyptus urophylla, observaram sintomas de deficiência de cálcio em folhas mais novas, com necrose no ápice foliar, sendo similares aos sinais obtidos nesta pesquisa com pimenta-longa. Epstein e Bloom (2006) afirmam que folhas e tecidos jovens desenvolvem sintomas de deficiências, porque o cálcio não é remobilizado na planta e que a deficiência de cálcio pode causar um aspecto gelatinoso nas pontas das folhas e nos pontos de crescimento, o que se deve à necessidade de pectato de cálcio para formação da parede celular.

\section{Magnésio}

Os sintomas de deficiência de magnésio foram caracterizados por clorose entre as nervuras secundárias das folhas mais velhas e necrose no ápice foliar (Figura 1), observados 53 dias após iniciados os tratamentos. Com a severidade da deficiência, ocorreu intensa queda de folhas, redução no crescimento da planta, em comparaçáo ao tratamento completo. Veloso e Muraoka (1993) descrevem sintomas semelhantes com a omissão de magnésio em pimenteira-do-reino, assim como Barroso et al. (2005), em mudas de teca. A clorose entre as nervuras, de acordo com Taiz e Zeiger (2009) ocorre porque a clorofila nos feixes vasculares permanece inalterada por períodos mais longos que a clorofila nas células entre os feixes, sendo essa sintomatologia observada, primeiramente, nos órgãos mais velhos.

\section{Enxofre}

Os sintomas de deficiência de enxofre surgiram aos 150 dias de início dos tratamentos, ocorrendo em folhas novas coloraçáo verde-amarelada, semelhante ao ocorrido na deficiência do nitrogênio, sendo que neste caso, a clorose se iniciou nas folhas mais velhas. Com a intensidade da deficiência, todas as folhas ficaram cloróticas (Figura 1) e a altura das plantas ficou bastante reduzida. Os sintomas de carência de $S$ observados foram concordantes com os descritos por Lavres Júnior et al. (2005), em plantas de mamona, cultivar Íris, e por Silva et al. (2009), em plantas de pinhãomanso. Conforme Malavolta (2006), a sintomatologia da carência de enxofre se deve ao fato de ser o nutriente absorvido pelas plantas, na forma $\mathrm{SO}_{4}^{-2}$, e transportado da base da planta para cima, em direção acrópeta, com pouca mobilidade, sendo por isso observado primeiro em órgãos mais novos.

\section{Boro}

Os primeiros sintomas de deficiência de boro surgiram 15 dias após a omissão e foram caracterizados por redução no crescimento das plantas, deformação e redução da área foliar, folhas coriáceas (acúmulo de carboidratos), com suas nervuras proeminentes, possivelmente devido ao aumento de lignina, e morte da gema terminal (Figuras 1). O boro é importante no crescimento vegetativo, um dos principais locais onde atua é na parede celular e na membrana citoplasmática, alterando suas propriedades mecânicas, principalmente na fase de crescimento. Malavolta (2006) cita haver uma relação estreita entre a nutriçấo de boro e a parede celular primária, visto estarem presentes nessa estrutura $90 \%$ do elemento contido na célula. Sintomas semelhantes de deficiência de boro foram observados por Silveira et al. (2002), em clone híbrido de Eucalyptus grandis $\mathrm{x}$ Eucalyptus urophylla, e Silva et al. (2009), em plantas de pinháo-manso.

\section{Cobre}

Não foram observados sintomas de deficiência de cobre, possivelmente decorrente da baixa exigência da pimentalonga nesse micronutriente; no período em que as plantas receberam a solução nutritiva completa diluída (primeiros 45 dias), antecedendo ao início dos tratamentos, devendo ter atendido boa parte de suas necessidades, não surgindo sintomas externos, ou seja, a soluçấo forneceu quantidade suficiente do nutriente.

\section{Ferro}

Sintomas de deficiência de ferro surgiram aos 200 dias de aplicados os tratamentos, com clorose em folhas novas, apresentando nervuras com reticulado fino, inicialmente de coloraçấo verde e posteriormente verde pálida, e, com a intensificaçâo da deficiência, clorose generalizada em todas as folhas da planta (Figura 1). Os sintomas de deficiência de ferro observados são semelhantes aos descritos por Silva $e t$ al. (2009), em plantas de pinhão-manso e por Lange et al. (2005), em mamona cultivar Íris. Garlet e Santos (2008), relatam que os sintomas de clorose observados em plantas deficientes em ferro podem ser causados por distúrbio na estrutura do cloroplasto, como consequência da inibição na síntese de lipídios.

\section{Manganês}

A omissão de manganês resultou em aparecimento de manchas amareladas entre as nervuras secundárias e terciárias, nas folhas mais novas de pimenta-longa e pequenas pontuaçôes cloróticas nas bordas das folhas (Figura 1), observados a partir de 210 dias após iniciados os tratamentos. Estes sintomas, observados em pimenta-longa, foram semelhantes aos descritos por Lange et al. (2005), em mamona, cultivar Îris.

De acordo com Kirkby e Römheld (2007) o Mn atua diretamente na fotossíntese e indiretamente na formação de carboidratos, assim, deficiências leves de Mn afetam a fotossíntese e diminuem o nível de carboidratos solúveis na 
planta. Já a deficiência mais severa de Mn ocasiona uma quebra na estrutura do cloroplasto que não pode ser revertida. Os cloroplastos são as mais sensíveis de todas as organelas celulares à deficiência de Mn, o que leva à desorganização do sistema lamelar e a sintomas visíveis de clorose.

\section{Zinco}

Os sintomas de deficiência de zinco surgiram aos 180 dias de iniciados os tratamentos. A omissão de zinco favoreceu a ocorrência de clorose inicial, entre as nervuras secundárias das folhas mais novas, as quais com a intensificação da deficiência perderam a coloraçấo verde. $\mathrm{O}$ limbo das folhas novas não se expandiu, convenientemente, ficando estreito e alongado e, num grau mais intenso da deficiência, toda a lâmina foliar amarelou (Figura 1). Veloso et al. (1998) relatam que o sintoma característico de deficiência de zinco em pimenta-doreino foi observado nas folhas novas, observação semelhante foi feita por Neves et al. (2004), estudando os sintomas visuais de deficiência de micronutrientes em umbuzeiro. $\mathrm{O}$ ácido indolacético (AIA) está intimamente relacionado com os sintomas de deficiência de zinco, portanto, quando ocorre deficiência desse micronutriente, menos AIA é sintetizado, como também, o que é produzido está sujeito a uma maior degradação oxidativa (Kirkby e Römheld 2007).

\section{Teores de nutrientes em folhas de pimenta-longa}

As omissóes isoladas de nitrogênio, fósforo, potássio, cálcio, magnésio, enxofre, boro, ferro, manganês e zinco reduziram os teores desses nutrientes nas folhas das plantas de pimenta-longa, exceto o micronutriente cobre, quando comparados com o tratamento completo (Tabela 2). Reduçáo de teores de nutrientes nas folhas em relação ao tratamento completo, também foi observado por Lange et al. (2005), em mamona cultivar Íris e por Silva et al. (2009), em plantas de pinhão-manso. Os teores de macronutrientes com base no tratamento completo apresentaram a seguinte ordem: $\mathrm{K}>$ $\mathrm{N}>\mathrm{Ca}>\mathrm{Mg}>\mathrm{P}>\mathrm{S}$ e dos micronutrientes $\mathrm{Fe}>\mathrm{Mn}>\mathrm{Zn}$ $>\mathrm{B}>\mathrm{Cu}$.

As plantas que receberam solução nutritiva completa apresentaram teores foliares de nitrogênio de $18,3 \mathrm{~g} \mathrm{~kg}^{-1} \mathrm{e}$ com sintomas visuais de deficiência, $8,9 \mathrm{~g} \mathrm{~kg}^{-1}$ (Tabela 2). Como não há na literatura pesquisas sobre teores foliares sem deficiências de nutrientes em pimenta-longa, a comparação dos teores obtidos é feita com a pimenteira-do-reino, que é da mesma família e com algumas plantas aromáticas. Portanto, o teor foliar de nitrogênio, obtido nesta pesquisa, é compatível com o determinado por Veloso e Muraoka (1993), que foi de $18,9 \mathrm{~g} \mathrm{~kg}^{-1} \mathrm{em}$ mudas de pimenteira-doreino (Piper nigrum) em condiçóes de casa de vegetaçáo. Além da redução no teor foliar de nitrogênio com a omissão desse nutriente, foi observada com as omissóes de fósforo, enxofre, cobre, ferro e manganês e aumento com a omissão de boro, quando comparado ao tratamento completo. A interaçáo entre nitrogênio e boro é citada por Malavolta (2006).

$\mathrm{O}$ teor foliar de fósforo nas plantas que apresentaram sintomas visuais de deficiência desse nutriente foi de $2,5 \mathrm{~g} \mathrm{~kg}^{-1} \mathrm{e}$ sem deficiência de $7 \mathrm{~g} \mathrm{~kg}^{-1}$ (Tabela 2), sendo 1,7 vezes superior ao teor em erva cidreira (Melissa officinalis) e de 2,3 vezes em hortelá-pimenta (Mentha pipereta) ambas, plantas aromáticas (Blank et al. 2006), indicando maior exigência de fósforo na pimenta-longa. Ocorreu aumento nos teores de fósforo com as omissóes de potássio e cálcio e redução com as omissóes de magnésio e boro, quando comparados ao completo.

Plantas que foram submetidas à omissão de potássio e que manifestaram os sintomas visuais de deficiência já descritos apresentaram teores foliares de $8,5 \mathrm{~g} \mathrm{~kg}^{-1}$, enquanto sem manifestação dos sintomas de 22,1 $\mathrm{g} \mathrm{kg}^{-1}$ (Tabela 2), valor um pouco superior ao obtido em pimenteira-do-reino de 21,9 g $\mathrm{kg}^{-1}$ por Veloso e Muraoka (1993) e em hortelá-pimenta de $21,2 \mathrm{~g} \mathrm{~kg}^{-1}$ por Rodrigues et al. (2004). Foi observada redução no teor foliar de potássio com a omissão de nitrogênio e aumento com a omissão de magnésio em relação ao tratamento completo, como consequência da interação antagônica entre esses nutrientes (Wallau et al. 2008b).

O teor foliar de cálcio nas plantas do tratamento completo foi de $15,7 \mathrm{~g} \mathrm{~kg}^{-1}$ (Tabela 2) valor um pouco inferior ao obtido por Blank et al. (2006) de $16,6 \mathrm{~g} \mathrm{~kg}^{-1} \mathrm{em}$ erva cidreira que recebeu a calagem. Com a omissão desse nutriente o teor foliar de cálcio foi de 10,2 $\mathrm{g} \mathrm{kg}^{-1}$ (Tabela 2), suficiente para ocorrer sintomas visuais de deficiência de cálcio. Foi constatado aumento no teor foliar de cálcio com a omissão de potássio e redução com a omissão de magnésio em relação ao tratamento completo, interação bastante conhecida entre esses nutrientes, devido à inibição competitiva, segundo Malavolta (2006).

As plantas que receberam soluçáo nutritiva completa apresentaram teor foliar de magnésio de $8,2 \mathrm{~g} \mathrm{~kg}^{-1} \mathrm{o}$ qual é 1,2 vezes mais alto do que o determinado por Galet e Santos (2008) em Mentha pipereta, e 1,7 vezes maior ao determinado por Amaral et al. (1999) em manjericão (Ocimum sp). O teor foliar obtido com a omissão de magnésio foi de $1,8 \mathrm{~g}$ $\mathrm{kg}^{-1}$ suficiente para as plantas mostrarem sintomas visuais de deficiência, já descritos. Redução nos teores foliares de magnésio, além da omissão com esse nutriente foi observada com a omissão de potássio, cálcio, enxofre e ferro em relaçáo ao completo.

O teor foliar de enxofre no tratamento completo foi de $5,1 \mathrm{~g} \mathrm{~kg}^{-1}$ (Tabela 2), sendo 2,8 vezes mais alto do que o obtido em pimenteira-do-reino por Veloso e Muraoka (1993), porém é inferior em 1,5 vezes ao determinado em plantas de Mentha pipereta por Galet e Santos (2008). Com a omissão de enxofre o teor nas folhas foi de $0,9 \mathrm{~g} \mathrm{~kg}^{-1}$. O teor foliar de enxofre aumentou com a omissão de fósforo, cálcio, cobre, ferro e manganês e reduziu além da omissão de enxofre com a 
de nitrogênio, quando comparados ao tratamento completo. Segundo Malavolta (2006) o teor foliar de fósforo está relacionado com o de enxofre e vice-versa e que a causa dessa interação são as proteínas.

O teor foliar de boro nas plantas que receberam a solução nutritiva completa foi de $42,2 \mathrm{mg} \mathrm{kg}^{-1}$ (Tabela 2) valor superior ao obtido por Veloso et al. (1998) de $34 \mathrm{~g} \mathrm{~kg}^{-1}$, porém é inferior aos determinados em erva cidreira de 58, $434 \mathrm{~g} \mathrm{~kg}^{-1}$ e em hortelā-pimenta de $54 \mathrm{~g} \mathrm{~kg}^{-1}$ (Blank et al. 2006). Plantas que apresentaram sintomas visuais de deficiência de boro o teor foliar foi de $15,5 \mathrm{mg} \mathrm{kg}^{-1}$. Ocorreu redução no teor foliar de boro com as omissões de fósforo, cálcio, enxofre, cobre, ferro e manganês em relação ao tratamento completo.

As plantas submetidas solução nutritiva completa apresentaram teores de ferro de $325 \mathrm{mg} \mathrm{kg}^{-1}$, valor compatível com os observados em hortelã-pimenta por Rodrigues et al. (2004) e inferior aos obtidos em erva-cidreira por Blank et al. (2006). Com omissão de ferro o teor foliar foi de $234 \mathrm{mg}$ $\mathrm{kg}^{-1}$ (Tabela 2) suficiente para manifestar os sintomas visuais de deficiência. Aumento no teor foliar de ferro foi observado com a omissão de cobre e além da omissão de ferro, redução com as omissões de potássio, magnésio, boro e manganês.

Com relação ao manganês, o teor foliar no tratamento completo foi de $100 \mathrm{mg} \mathrm{kg}^{-1}$, mesmo valor obtido por Veloso et al. (1998) em plantas de pimenteira-do- reino, porém inferior em 1,6 vezes ao determinado por Garlet e Santos (2008) em hortelá-pimenta. $\mathrm{O}$ teor foliar em plantas que apresentaram deficiências visuais em manganês foi de $55 \mathrm{mg} \mathrm{kg}^{-1}$. O teor na folha de manganês aumentou com a omissão de potássio e reduziu com as omissóes de magnésio, enxofre, boro, cobre e zinco, quando comparado ao tratamento completo.

Foi de $61,5 \mathrm{mg} \mathrm{kg}^{-1}$ o teor foliar de zinco nas plantas do tratamento completo ( tabela 2), o qual é superior em 1,1 vezes ao obtido por Veloso et al. (1998) em pimenteira-do-reino, 2 e 2,2 vezes nas plantas de erva-cidreira e hortelá-pimenta, respectivamente (Blank et al. 2006). Com a omissão de zinco, o teor foliar foi de $53 \mathrm{mg} \mathrm{kg}$, ocorrendo sintomas visuais de deficiência. Aumentos nos teores foliares de zinco foram observados com as omissões de fósforo, cálcio, magnésio e manganês e redução com as omissôes de enxofre, boro e ferro. Resultados de pesquisas mostrando a interação fósforo e zinco tem sido, relatados comumente pela literatura e que a interação pode ser antagônica. A interação zinco e manganês variam e dependem da cultura e do manejo e, portanto a correlaçáo pode ser positiva, negativa ou inexistente.

\section{CONCLUSÕES}

As omissões individuais de nutrientes na solução nutritiva com exceção do cobre promovem a ocorrência de sintomas visuais de deficiência em plantas de pimenta-longa acompanhada da redução no teor foliar dos seus respectivos nutrientes.

Nas plantas de pimenta-longa os sintomas visuais de deficiência de nitrogênio e boro são os primeiros a se manifestarem, quando da omissáo total dos nutrientes.

Tabela 2 - Teores de macro e micronutrientes $\left(\mathrm{g} \mathrm{kg}^{-1}\right.$ e mg kg-1) em folhas de pimenta-longa (Piper hispidinervum C. DC.), em função dos tratamentos em solução nutritiva completa e com omissão de macro e micronutrientes.

\begin{tabular}{|c|c|c|c|c|c|c|c|c|c|c|c|}
\hline \multirow{2}{*}{ TRATAMENTO } & $\mathrm{N}$ & $P$ & $\mathrm{~K}$ & $\mathrm{Ca}$ & $\mathrm{Mg}$ & S & $B$ & $\mathrm{Cu}$ & $\mathrm{Fe}$ & $\mathrm{Mn}$ & $\mathrm{Zn}$ \\
\hline & \multicolumn{6}{|c|}{ 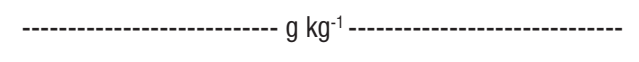 } & \multicolumn{5}{|c|}{ 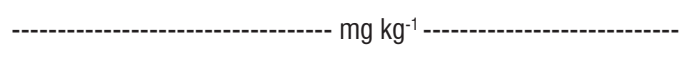 } \\
\hline Completo & $18,3^{\text {ns }}$ & $7^{\mathrm{ns}}$ & $22,1^{\mathrm{ns}}$ & $15,7^{\text {ns }}$ & $8,2^{\text {ns }}$ & $5,1^{\text {ns }}$ & $42,2^{\text {ns }}$ & $34,0^{\mathrm{ns}}$ & $325^{\mathrm{ns}}$ & $100^{\mathrm{ns}}$ & $61,5^{\mathrm{ns}}$ \\
\hline Omissão de N & $8,9^{*}$ & $7,1^{\text {ns }}$ & $8,6^{*}$ & $12,1^{*}$ & $7,4^{\text {ns }}$ & $2,8^{*}$ & $45^{\mathrm{ns}}$ & $23^{*}$ & $201^{*}$ & $94^{\mathrm{ns}}$ & $60,7^{\text {ns }}$ \\
\hline Omissão de P & $13,3^{*}$ & $2,5^{\star}$ & $23,9^{\text {ns }}$ & $16,9^{\text {ns }}$ & 8,9 ns & $7,2^{*}$ & $35,2^{*}$ & $24^{*}$ & $315^{\mathrm{ns}}$ & $109^{\mathrm{ns}}$ & $77,2^{*}$ \\
\hline Omissão de K & $19,8^{\text {ns }}$ & $8,8^{*}$ & $8,5^{*}$ & $19,7^{*}$ & $2,4^{*}$ & $5,4^{\text {ns }}$ & $47,5^{\text {ns }}$ & $23^{*}$ & $245^{*}$ & $222^{*}$ & $61^{\text {ns }}$ \\
\hline Omissão de Ca & $19,2^{\text {ns }}$ & $9,1^{*}$ & $24,2^{\text {ns }}$ & $10,2^{*}$ & $2,1^{*}$ & $5,9^{*}$ & $32^{\star}$ & $28,5^{*}$ & $267^{\mathrm{ns}}$ & $86^{\mathrm{ns}}$ & $78^{*}$ \\
\hline Omissão de Mg & $19,7^{\text {ns }}$ & $4,1^{*}$ & $39,2^{*}$ & $13,5^{*}$ & $1,8^{*}$ & nd & $38,5^{\text {ns }}$ & $10^{*}$ & $203^{*}$ & $73,2^{*}$ & $92,7^{*}$ \\
\hline Omissão de S & $10,9^{*}$ & $6,6^{\text {ns }}$ & $22,3^{\text {ns }}$ & $16,7^{\text {ns }}$ & $3,4^{*}$ & $0,9^{*}$ & $14^{\star}$ & $33,9^{\text {ns }}$ & $295^{\mathrm{ns}}$ & $67,2^{*}$ & $37,2^{*}$ \\
\hline Omissão de B & $22,6^{\star}$ & $4,8^{*}$ & $22,9^{\text {ns }}$ & $12,4^{*}$ & $8,7^{\text {ns }}$ & $4,8^{\text {ns }}$ & $15,5^{\star}$ & 33,9 ns & $136^{*}$ & $43^{*}$ & $51^{*}$ \\
\hline Omissão de Cu & $14,4^{*}$ & 6,9 ns & $25,4^{\text {ns }}$ & $14,3^{\text {ns }}$ & 7,9 ns & $6,2^{*}$ & $28,2^{*}$ & $34^{\mathrm{ns}}$ & $385^{*}$ & $73,5^{*}$ & $67,2^{\text {ns }}$ \\
\hline Omissão de Fe & $13,5^{\star}$ & $6,3^{\text {ns }}$ & $23,1^{\text {ns }}$ & $14,6^{\text {ns }}$ & $1,8^{*}$ & $6,1^{*}$ & $34,2^{\star}$ & $33,9^{\text {ns }}$ & $234^{*}$ & $107^{\text {ns }}$ & $50,5^{*}$ \\
\hline Omissão de Mn & $14,1^{*}$ & $7,2^{\text {ns }}$ & $24^{\mathrm{ns}}$ & $13,6^{*}$ & 8,9 ns & $6,2^{*}$ & $35^{\star}$ & $35^{\mathrm{ns}}$ & $245^{*}$ & $55^{\star}$ & $75,7^{*}$ \\
\hline Omissão de Zn & $17,2^{\text {ns }}$ & $7,2^{\text {ns }}$ & $22,6^{\text {ns }}$ & $16,1^{\text {ns }}$ & $9,1^{\text {ns }}$ & $5,1^{\text {ns }}$ & $37,5^{\text {ns }}$ & $34,3^{\text {ns }}$ & $337^{\mathrm{ns}}$ & $84,5^{*}$ & $53^{*}$ \\
\hline C.V (\%) & 9,4 & 9,2 & 6,7 & 6,7 & 9,6 & 8,1 & 7,7 & 7,2 & 10,9 & 7,8 & 6,0 \\
\hline DMS & 3,1 & 1,2 & 3 & 2 & 1,1 & 0,8 & 5,3 & 4,2 & 59,3 & 14,9 & 7,9 \\
\hline
\end{tabular}

* Médias seguidas por um asterisco na mesma coluna diferem significativamente do completo, ao nível de $5 \%$ de probabilidade pelo teste de Dunnett.

ns Médias não significativas em relação ao tratamento completo, ao nível de $5 \%$ de probabilidade pelo teste de Dunnett.

nd $=$ não determinado. 


\section{BIBLIOGRAFIA CITADA}

Amaral, J.F.T. do; Fonseca, A.F.A. da; Martinez, H.E.P.; Pereira, P.R.; Fontes, P.C.R. 1999. Deficiências de macronutrientes, Fe e B em manjericâo (Ocimum sp.) em cultivo hidropônico. Revista Ceres, 46(265): 297-308

Barroso, D.G.; Figueiredo, F.A.M.M. de A.; Pereira, R. de C.; Mendonça, A.V.R.; Silva, L. da C. 2005. Diagnóstico de deficiências de macronutrientes em mudas de teca. Revista Árvore, 29: 671-679.

Benedetti, E.L.; Wink, C.; Santin, D.; Sereda, F.; Roveda, L.F.; Serrat, B.M. 2009. Crescimento e sintomas em mudas de espinheirasanta com omissão de nitrogênio, fósforo e potássio. Curitiba, PR. Revista Floresta, 39(2): 335-343.

Blank A.F; Oliveira A.S.; Arrigoni-Blank M.F.; Faquin V. 2006. Efeitos da adubação química e da calagem na nutriçáo de melissa e hortelãpimenta. Horticultura Brasileira 24: 195-198.

Bolle - Jones, E.W. 1954. Cooper, its effects on the growth of rubber plant (Hevea b rasiliensis). Plant and soil, 10(2): 150-178.

Brasil, E.C.; Viégas, I.J.M. 1998. Efeito da adubação mineral na produção de matéria seca de pimenta-longa (Piper hispidinervum). Belém: Embrapa - CPATU, 4pp. (Embrapa-CPATU. Pesquisa em Andamento, 180).

Camargos, S. L.; Muraoka, T.; Fernandes, S. A. P.; Salvador, J. O. 2002. Diagnose nutricional em mudas de castanheira-do-brasil. Revista Agricultura Tropical, Cuiabá, 6(1):81-96.

Epstein, E.; Bloom, A.J. 2006. Nutrição mineral de plantas: princípios e perspectivas. Londrina: Editora Planta. 403pp.

Galet, T.M.B.; Santos, O.S. dos. 2008. Solução nutritiva e composição mineral de três espécies de menta cultivadas no sistema hidropônico. Ciência Rural, 38(5).

Gonçalves, F.C.; Neves, O.S.C.; Carvalho, J.G. de. 2006. Deficiência nutricional em mudas de umbuzeiro decorrente da omissão de macronutrientes. Pesquisa Agropecuária Brasileira, 41: 1053-1057.

Kirkby, E.A.; Römheld, V. 2007. Micronutriente na fisiologia de plantas: funçóes, absorção e mobilidade. International Plant Nutrition Institute. Informaçóes Agronômicas, 118: 1-24.

Lange, A.; Martines, A.M.; Silva, M.A.C.; Sorreano, M.C.M.; Cabral, C.P.; Malavolta, E. 2005. Efeito de deficiência de micronutrientes no estado nutricional da mamoneira cultivar Íris. Pesquisa Agropecuária Brasileira, 40: 61-67.

Lavres Junior, J.; Boaretto, R.M.; SILVA, M. L.S.; Correia, D.; Cabral, C.P.; Malavolta, E. 2005. Deficiências de macronutrientes no estado nutricional da mamoneira cultivar Iris. Pesquisa Agropecuária Brasileira, Brasília, 40(2): 145-151.

Maffeis, A.R.; Silveira, R.L.V.A.; Brito, J.O. 2000. Reflexos das deficiências de macronutrientes e boro no crescimento de plantas, produção e qualidade de óleo essencial em Eucalyptus citriodora. Scientia Forestalis, 57: 87-98.

Malavolta, E. 2006. Manual de nutrição mineral de plantas. São Paulo: Editora Agronômica Ceres, 638 pp.

Neves, O.S.C.; Sá, J.R. de; Carvalho, J.G. de. 2004. Crescimento e sintomas visuais de deficiência de micronutrientes em umbuzeiros. Revista Brasileira de Fruticultura, 26: 306-309.
Rodrigues, C.R.; Faquin, V.; Trevisan, D.; Pinto, J.E.B.P.; Bertolucci, S.K.V.; Rodrigues, T.M. 2004. Nutrição mineral, crescimento e teor de óleo essencial da menta em solução nutritiva sob diferentes concentraçóes de fósforo e épocas de coleta Horticultura Brasileira, Brasília, 22(3): 573-578.

Santiago, E.J.A.; Pinto, J.E.B.; Castro, E.M.; Lameira, O.A.; Conceição, H.E.O.; Gavilanes, M.L. 2001. Aspectos da anatomia foliar da pimenta-longa (Piper hispidinervum) sob diferentes condiçóes de luminosidade. Ciência e Agrotecnologia, Lavras, 25(5): 1035-1042.

Sarcinelli, T.S.; Ribeiro Júnior, E.S.; Dias, L.E.; Lynch, L. de S. 2004. Sintomas de deficiência nutricional em mudas de Acacia holosericea em resposta à omissão de macronutrientes. Revista Árvore, 28: 173-181.

Silva, E.B.; Tanure, L.P.P.; Santos, S.R; Resende Júnior, P.S. 2009. Sintomas visuais de deficiências nutricionais em pinhão-manso. Pesquisa Agropecuária Brasileira, Brasília, 44(4): 392-397.

Silva, R.C.B. da; Scaramuzza, W.L.M.P.; Scaramuzza, J.F. 2011. Sintomas de deficiências nutricionais e matéria seca em plantas de nim, cultivadas em solução nutritiva. Cerne, Lavras, 17(1): 17-22.

Silveira, R.L.V.A.; Moreira, A.; Takashi, E.N.; Sgarbi, F.; Branco, E.F. 2002. Sintomas de deficiência de macronutrientes e de boro em clones híbridos de Eucalyptus grandis com Eucalyptus urophylla. Cerne, 8(2): 107-116.

Sousa, M.M.M.; Lédo, F.J.S.; Pimentel, F.A. 2001. Efeito da adubação e do calcário na produção de matéria seca e de óleo essencial de pimenta-longa. Pesquisa Agropecuária Brasileira, 36(3): 405-409.

Taiz, L., Zeiger, E. 2009. Plant physiology. $4^{\text {th }}$ edn. Artmed, Porto Alegre, $848 \mathrm{p}$.

Veloso, C.A.C; Muraoka, T. 1993. Diagnóstico de sintomas de deficiência de macronutrientes em pimenteiras do reino (Piper nigrum L.) Scientia Agrícola, 50(2): 232-236.

Veloso, C.A.C; Muraoka, T; Malavolta, E; Carvalho, J.C. 1998. Deficiências de micronutrientes em pimenteira do reino. Pesquisa Agropecuária Brasileira, 33(11): 1883-1888.

Viégas, I. de J. M.; Naiff, A.P.M.; Conceição, H.E.O.; Lobato, A.K. da S.; Frazão, D.A.C; Cordeiro, R.A.M. 2011. Visual symptoms, growth and nutrients of Alpinia purpurata plants exposed to N, P, K, Ca, Mg and S deficiencies. Journal of Food, Agriculture \& Environment. 9(3\&4): 1048 - 1051.

Wallau, R.L.R. de; Borges, A.R.; Almeida, D.R. de; Camargos, S.L. 2008a. Sintomas de deficiências nutricionais em mudas de mogno cultivadas em solução nutritiva. Revista Cerne, Lavras, 14(4): 304-310.

Wallau, R.L.R. de; Soares, A. de P.; Camargos, S.L. 2008 b. Concentração e acúmulo de macronutrientes em mudas de mogno cultivadas em solução nutritiva. Revista de Ciências AgroAmbientais, Alta Floresta, 6(1): 1- 12.

Recebido em: 26-04-2011

Aceito em: 18-02-2012 